\title{
THE INFORMAL SECTOR AND PERIPHERAL CAPITALISM: THE CASE OF TANZANIA
}

\section{Manfred Bienefeld*}

The emergence of the term, 'the informal sector' must be understood in the context of the concern with development in general. Early hopes that the modern enclaves of the ex-colonies would grow apace, and would absorb the majority of the labour force, were soon dashed. The failure of this 'modernization' process to absorb significant proportions even of the annual net additions to the labour force, together with the failure of the rural areas to play the role of infinitely adaptable, passive labour reserves, soon led to the emergence of acute problems of urbanization. This brought growth rates of urban labour forces far exceeding the capacity to create 'modern sector' jobs. Analysers began speaking of an unemployment problem, and the more cautious spoke of an underemployment problem. Eventually, the difficulty of defining and identifying these concepts, and of integrating them into a broader conception of the process which was creating them, led to the identification of a 'sector' of the economy which incorporated all of the problems of underemployment and unemployment in one complex and fluid socio-economic structure. ${ }^{1}$ While this reformulation had the undoubted advantage of cutting short the endless and involuted academic debate about what was unemployment or underemployment, and just how involuntary either had to be in order to be 'real' it did nothing in and of itself to establish this new concept as anything but an essentially descriptive term whose analytic significance has yet to be established.

In order for this concept to attain analytic value it is necessary that it be shown that it represents a part of the economy which has its own dynamic of development, which responds differently to certain

* Manfred Bienefeld is a Fellow of the Institute of Development Studies.

1 Keith Hart, 'Informal Income Opportunities and Urban Employment in Ghana', Journal of Modern African Studies, vol. II no. 1, 1973;Employment Incomes and Equality: a strategy for increasing productive employment in Kenya, ILO, Geneva, 1972. 
socio-economic changes and which generates different types of changes than the other sectors, from which it is distinguished.

This means that the fact that the 'sector' in question may be low-income, poorly capitalized or inward looking cannot serve as a definition of it. The definition must assess the significance of these particular characteristics, with reference to the process which has produced them.

\section{The Problem of Definition}

There are essentially two bases on which to build a sectoral analysis of an economy. One entails the identification of different modes of production in the Marxist sense, and concerns itself with the articulation of these modes of production. The other sees the problem in terms of a discontinuity within the capitalist mode of production in which different sectors of the capitalist economy relate to each other in an unequal manner.

The first alternative was long discussed in terms of 'traditional' and 'modern'. This lent itself to views which saw undeveloped, backward areas impeding the progress of modernisation through their economically irrational cultural and social structure. A much more promising approach sees the problem in terms of an interaction between different modes of production in which various modes adapt to each other, each becoming dependent on the other and each losing its identity and independence to some degree.

The modes of production referred to here involve on the one hand, a capitalist sector deeply integrated in to an in ternational economy, and on the other, one of a variety of pre- or non-capitalist modes, each more or less deeply transformed through its relations with the former. The form which this symbiosis takes is historically specific to a degree, in that it depends on the resource base and the level of the forces of production of the capitalist sector, on the socio-political framework within which capital operates, on the extent of its accumulation and local growth, and on the nature of the non-capitalist mode of production with which it interacts. Nevertheless, the question arises whether beyond this historical specificity, there is a common pattern to be discerned. 
The second basis for a 'sectoral' analysis has been developed by a variety of economists who have focused on the imperfections in the market, which have to exist if sectoral differences were to be anything other than pure reflections of differential productivities, directly related to differences in the level of the forces of production.

Parts of this debate are again echoed in the Marxist debate. Hence the issue is whether the values (in terms of embodied labour) exchanged in the market may be systematically unequal beyond the superficial equality of their market prices. The issue is clearly important since it determines whether the differentials between different groups are merely the result of differential productivities, and different costs of reproduction of labour or whether they are also due to an 'inequitable' system of valuation. If it is the former, the problem can be dealt with by raising the physical productivity of those lagging behind. If it is the latter, there would also need to be sufficient control of the 'market' by the lagging sections of the economy to ensure that the benefits of greater productivity were not simply alienated through the exchange relationship.

Ultimately the question is of interest because it bears on the question of accumulation and on the possibilities of developing the forces of production. It is clearly of great importance to decide to what extent the small scale sectors of the economy, which include all of the most desperately poor among their number, are themselves engaged in a process of accumulation and capital deepening, and to identify correctly those forces which are constraining that development at present. There is little doubt that mobilization of resources, and hence accumulation, on a broader front is essential if current patterns of development are to be broken. Unfortunately, it is equally clear that these very patterns of development are limited by international developments which any one country will be hard-pressed (or powerless?) to alter.

The tentative framework of this paper assumes that many small scale operators are engaged in a process of production and of technological development but that their ability to develop cumulatively over extended periods is limited: by their being exploited through the terms of trade; by their dependence on large scale industry for inputs (of ten illegally obtained); and by the fact that when the markets they serve 
grow beyond a certain size this will not be a gradual but accelerating stimulus to further development of the forces of production. Instead it will trigger a discontinuous shift to 'international' technology which will incorporate this market by virtue of its efficiency and/or its market power, the latter based on effectively unlimited access to capital and on the establishment of brand name products through heavy advertising.

The net result of this situation is an appearance of virtual stagnation among petty producers, though a more dynamic analysis would possibly reveal a process of growth and destruction. Certainly the very sketchy data presented here for Tanzania can do no more than give a rough indication of the consistency of its findings with such a scenario. Further analysis of this data which is now in progress will enable some further light to be thrown on these issues, but ultimately it is clear that detailed historical studies of the development of particular industrial sectors will be required if this process of growth and destruction is to be more clearly understood.

The critical issues of the debate emerge in several parts: what are current income differentials and to what extent are these merely a reflection of differential productivities or differential costs of the reproduction of labour; and secondly to what extent is accumulation of surplus, and hence the development of the forces of production and of productivity, taking place in the 'exploited' sector, if such a sector can be identified.

\section{Low Income Wage Earners}

What income differentials exist in the urban areas of Tanzania? The differentials revealed by the survey ${ }^{2}$ were large, even within the wage earning sector. The top quintile of wage/salary earners received 53.6 per cent and the bottom quintile 6.6 per cent of the total wage bill. This disparity increased substantially when non-wage earners and the unemployed were included. With these groups included, the top quintile received around 56 per cent of personal incomes. What sorts of income earning activities yield the very lowest incomes? The evidence suggests that these are wage earners, clustered in certain parts of the

2 The data presented here are drawn from M.A. Bienefeld and R.H. Sabot, National Urban Mobility, Employment and Income Survey of Tanzania, 1971, (NUMEIST) Economic Research Bureau, University of Dar es Salaam, vols. I-IV, 1972. 
service sector, casual wage earners spilling over into a few other industrial areas, and self-employed. What it is hoped to do in this brief discussion, is to identify possible explanations for this pattern and further, to make a few tentative remarks concerning the apparent possibilities of accumulation and growth in various parts of this rather heterogeneous group.

If we look first at the wage-earners, it is important to note that those with the lowest incomes were extraordinarily concentrated in certain sub-sectors. At the time of the survey, the minimum wage in Dar es Salaam was Shs 170 per month. Six per cent of all wage earners earned less than Shs 150. But 22 per cent of those employed in shops, hotels, bars or domestic service fall in this category. This meant that 76 per cent of these very low wage earners in Dar were to be found in these four sub-categories of service. For the six 'up-country' towns the pattern was similar, if somewhat less pronounced. The remainder of those earning less than the minimum wage were widely scat tered over the other industrial sectors. Almost half of them were casual employees. In addition, within these lowest groups more than 50 per cent of workers received no fringe benefits of any kind, while for other wage earners comparable proportions lay well below 25 per cent.

By way of explanation one can point out that all of the lowest income jobs (ignoring casual non-service workers for the moment) involved the sale of labour power in direct contact with the consuming customeri.e. labour which was not mediated through embodiment in a commodity, and in the case of domestic servants, labour which was also not purchased in order to produce surplus value. This means that in all of these activities, output, and hence 'productivity', tend to be closely identified with the amount of time spent at work. Productivity increases are hard to achieve, and, if achieved, hard to establish, so that income changes based on the development of productivity are less likely. If other industries raise productivity but do not pass all of the 'benefits' of such increases on to the consumer through cheapened commodities, then a form of 'unequal exchange' will develop which discriminates against the service workers described here. The resulting income differentials are sanctioned by the fact that the establishments in which the lowest wage earners work are small, and not effectively subject to wage and social security legislation. 
Finally those working in these areas are further hampered by the relatively unskilled nature of their work. This, combined with the great difficulty of organizing or unionizing workers whose jobs are physically scattered, exposes them to the full force of labour market competition. The large number of applicants who regularly offer themselves for domestic service jobs in Dar at very cheap rates is merely one very visible part of that process.

As to casual wage earners, it should be pointed out that these overlapped substantially with employment in the above economic sectors. After construction (37 per cent), domestic service had the highest proportion of casual employees. Often this involved casual labour contracts offered by employers in order to escape the extensive social security arrangements attendant upon regular employment. In addition, a set of 'casual' jobs was found in industries involving irregular work. In these cases the use of casual labour allowed the industries to shift the cost of this irregularity on to the wage earners, emphasizing the weakness of the bargaining position of unskilled labour in a surplus labour situation.

The significance of casual labourers in this context lies precisely in the fact that they represent an area of the economy where employers still find it possible - or advisable - to treat labour as a homogeneous undifferentiated commodity to be purchased without regard to turnover rates or the attendant questions of training, skill, quality control and commitment to the job or firm. The advantage, such as it is, of this kind of labour market, lies in the fact that it reduces labour to a truly variable cost, which can be geared to demand requirements on a daily basis.

This kind of hiring practice, only too familiar from colonial days, has a technological basis. It is not feasible in most pre-capitalist, or pre massproduction enterprises, and it ceases to be sensible in very highly capital intensive operations where the benefits of stable, experienced workers outweigh the costs involved in paying the necessary premium to achieve such stability. In Marxist terms this reflects a change in emphasis to the extraction of relative, rather than absolute, surplus value. 
However, while many industries move away from such labour practices for most of their workers, casuals often continue to be used in a fringe of more occasional jobs, through which the costs of demand fluctuations can continue to be partially passed on to the workers. In conclusion it might be noted that there are forms of sub-contracting which may at times be used to achieve the same ends as the use of casual labour, with the added disadvantage to the worker that he not only bears the costs of irregularity of demand, but he is effectively removed from what legal protection workers (i.e. employees) may have been able to obtain, and the common interests which tend to bind him to his fellow workers are dissolved. Instead he is pitted against each of them in relentless competition. Recommendations to extend sub-contracting as a means of encouraging 'informal sector' activities ought to be seen in this light.

\section{Self-Employment}

A substantial proportion of those earning less than the statutory minimum wage were found to be self-employed. Indeed almost half of such activities yielded incomes of less than Shs 150 per month. ${ }^{3}$ On the other hand, a quarter yielded incomes of Shs 350 and more, and 10 per cent produced incomes of at least Shs 1,000 per month. This emphazised the obvious point that the self-employed are not a homogeneous group, whose position in the economy could be characterized in an undifferentiated manner.

The fact is that the truly marginal persons eking out a meagre income were here lumped together with entrepreneurs accumulating capital. It was clearly necessary to separate these groups, and to look in particular at the two extremes, namely the 45 per cent who earned less than Shs 150 per month and the 11 per cent earning Shs 1,000 and more.

For six distinct types of self-employment - crafts and manufacture, construction, street-trading, hotel and bar keeping, house rental and farming - more than one in three participants earned less than Shs 150

3 Income figures for the self-employed were marred by a high rate of non-response, for some groups as high as 50 per cent. The figures are presented in detail in M.A. Bienefeld, The Self-employed of Urban Tanzania, IDS Discussion Paper no. 54, IDS, 1974. 
per month, and in house rental and street-trading the proportion was more than fifty per cent. At the other end of the spectrum shopkeepers included a large proportion (35 per cent) who earned at least Shs 1,000 per month and who could therefore possibly be accumulating some capital. In addition, 10 per cent of craftsmen were in this position, but in all other groups the proportion was well below that level.

In order to begin to locate each of these sub-groups in the urban economy, and thus to begin an analysis of what factors account for their present circumstance and their potential development, it is useful to divide them into three groups - crafts and manufacture; retailing services, including street-trading, shopkeeping and bar-keeping; and the provision of accommodation, including construction and house rental. Each of these areas has its own problems and possibilities. It should be noted that the distribution and services group overlaps with the sectors including the bulk of the lowest income wage earners.

The first group, crafts and manufacture, represents potentially the most important set of activities. This is where (material) use-values are produced and where the forces of production experience their most extensive development. This brings in its train the need for more extensive facilities for finance and distribution, and generates the surplus which accelerates the process of accumulation and the rate of productivity increase. Unfortunately, only a small proportion (10 per cent) of those engaged in this set of activities earned incomes suggesting that they 'might' be engaged in a process of capital accumulation and of the development of the forces of production.

To gain some perspective on this observation it is necessary to step out of the confines of the static survey picture. The manufacturing sector in Tanzania has grown substantially since independence, from a very small beginning. This growth involved the development of a considerable number of local enterprizes, invariably owned and operated by members of the local Asian or European communities. This was a sign that accumulation was taking place, and since the communities in question had originally derived their capital largely from trading, it also suggested the existençe of a mechanism through which trading profits were utilized to accelerate the accumulation of surplus in production. 
The 'local' activities were most vigorously extended in the areas of food processing, clothing, and other more minor activities like furniture-making, soap-making, etc. On the whole such operations were not technologically sophisticated, relied primarily on local inputs and produced largely for the local (East African) market. Certainly their existence constituted prima facie evidence that capitalist development was not only possible, but that it was in fact taking place, and that local entrepreneurs could play a role in this process.

Nevertheless the expansion of international capital has meant that today, most branches of manufacturing are dominated by firms which are extensions of the in ternational production network, either in terms of their technology, their management and/or their ownership. What this has meant for local entrepreneurs has depended on the way in which the now dominant firms entered the economy. Although this process has been very little studied in Tanzania, certain general observations can be attempted.

The manner and the circumstances of this penetration of foreign capital may itself yield some valuable insights into Tanzania's much discussed 'socialism'. The fact that the 'local' industrial and commercial sectors were entirely dominated by minority communities has to be considered a factor which facilitated the entry and expansion of international capital. Certainly, if the majority community was to gain some control of these sectors within a reasonable period, the establishment of international firm subsidiaries operating with state participation quite clearly emerged as a very attractive alternative. Indeed it was this alliance between the state and international enterprise which created the situation in which the relative economic power of the minority communities came not to be reflected fully at the political level.

Of course this argument does not imply that international capital penetrates only economies where such preconditions exist, nor is it meant to suggest that Nyerere's socialist endeavours have not been genuine and well-conceived. What it does help to clarify is the reason why it has been possible to move along this apparently socialist road when the political basis for such a policy seems woefully inadequate. The answer this suggests is that it is merely state participation which has been supported. This also explains why 'socialist' measures which 
extended beyond this limited aim became the focus of opposition viz. workers' participation, the Party Guidelines of 1971, the 1974 Income Tax Act, the creation of a mass-based movement towards 'Ujamaa'.

If these factors do something to explain the manner in which foreign capital entered the economy, one must be clear also that there were often good economic reasons why external capital was given preference. Local business was often family based and hence restricted in its potential growth by the limits imposed by the family's size.

Furthermore the interdependence of various enterprises combined with the cohesion of the minority communities and the limited extent of the market to make entry by other entrepreneurs all but impossible and to make oligopolistic practices inevitable. When one adds that with this kind of 'local' ownership the outflow of capital was already a significant problem, though its precise dimensions are naturally not known, the apparently higher level of productivity of foreign producers was seen as a virtually unqualified blessing. Indeed, questions as to whether these potential benefits were realized or, whether the consumer, or indeed the society, reaped the benefits, were rarely asked. Certainly there were cases, such as the soap industry in Kenya, grain storage, beer brewing and the baking of bread in Tanzania, where even purely economic analysis would have been hard pressed to justify the heavy investment in centralized facilities which has occurred.

Unfortunately, even those international producers who bring no economic advantage of ten thrive. The reasons why, once admitted, foreign producers displace local producers even if they have no economic (i.e. efficiency) advantage, must be sought on the one hand, in their use of advertising, packaging and surface finishing, which have particular leverage due to the 'more modern is better' mentality of the 'imported civilization', and on the other hand, in the ability of the 'modern' product to undersell its competitors (even if only temporarily) and to force the hand of the government - especially if it is a partner - to give it concessions to this end.

This process determines the limited development potential of the small scale productive sector. It ex tracts surplus from this sector through exchange, and hence limits the extent to which accumulation takes 
place in that sector. When such accumulation takes place nonetheless, and when this leads to capital deepening and the introduction of capital on a larger scale, such developments will often be subjected to the introduction of a very much more capital intensive technology. This may occasionally happen through a local en trepreneur, but more often it involves the direct participation of the government and/or a foreign firm.

The effect is similar regardless of the form it takes: the linkages upon which the original enterprises were based are broken, and they are rarely fully replaced by others; the surplus generated in this new process is not partially drained off to pay for the technology; the 'saving' of labour due to the greater efficiency is a curse, not a blessing; the capital (liquid) which has been accumulated and embodied in this activity (realized, non-malleable capital) is virtually turned to scrap; the capacity to develop the technology employed is greatly impaired, if not destroyed. Though the surplus created by the new process may be greater than that generated before, and even though this surplus may sometimes be greater net of surplus drain, the relevant comparison is with the surplus that would have been created by the activity in question and all of its attendant linked activities, if the process of capital deepening had not been interrupted.

If these notes may be said to sketch the outlines of the factors which determine the upper limits which inhibit local accumulation, two points should be stressed before continuing. The fact that distinct minority groups controlled local manufacture in Tanzania was locally important, but it is not being suggested that the argument depends upon this circumstance. The groups which control capital are always distinct in that they constitute a class. The significance of this particular case lies in the weakening of the symbiosis between local capital and the controllers of the state apparatus, so that the usual, limited conflict of interest between the state and international capital was less pronounced. It need not be pointed out that the intrusion of foreign capital occurs even when such a background does not exist, and one may add that in Tanzania, as elsewhere, many local capitalists have resolved their dilemma by linking up with foreign manufacturers - and, if possible, with the government as well. However, the Tanzanian pattern of ownership may well be important in explaining the high 
degree of 'apparent autonomy' of the Tanzanian state, in that it explains the divorce of the state from local capital.

The second point is that the entry of foreign capital obviously does not always displace local production, and indeed at times it is responsible for its beginning - i.e. the production of local cloth led to the forward linkage development of numerous clothing manufacturers. The problem is that any such linked developments are themselves open to the threat of entry by a much more highly mechanized producer into their market. Indeed the more successful a local group of producers are, the more likely it is that the introduction of 'in ternational technology' may become profitable in the market defined (or created) by them.

The local craftsmen or small scale manufacturers are thus in one of three situations: they are either pursuing their particular activity as an essentially temporary expedient; they are producing in the interstices of a market not reached by an existing 'modern' producer, being therefore in a rather static situation and limited in the extent to which accumulation and capital deepening is possible; or they are in an 'open', growing market moving in a direction where the threat of lethal competition forces them to seek a foreign firm and/or the government as a partner in order to survive. In every case the appearance of the small-scale manufacturing sector that meets the observer's eye, is that of a rather stagnant, non-accumulating part of the economy.

In the survey this apparent sluggishness of the sector was reflected in the combination of a generally low level of income and production with a high degree of stability and seniority among participants. These were characterized by a concentration of participants ( 74 per cent compared to 58 per cent of wage earners) in the mature working age bracket 25 to 49 years; a low proportion 'looking for work' (12 per cent compared to 13 per.cent of wage earners); a high proportion engaged in the activity for three years or more (67 per cent compared to 47 per cent of wage earners in their present jobs). This high degree of at tachment in the absence of much evidence of rapid accumulation, reflected the fact that 62 per cent of respondents earned more than Shs 150 per month, and hence were at least earning the minimum wage. This was particularly significant in view of the fact that 67 per cent of the total number thus engaged had had no more than four years of education (wage earners: 41 per cent). 


\section{The Retailers}

This group made up almost one half of all non-wage earners in the survey. In terms of the previous discussion this is not unexpected, since this sector is relatively immune to competition from highly centralized, capital intensive operations, at least at present levels of consumption and mobility.

It is true that the development of the forces of production must begin with the accumulation of surplus, and that such surplus may be originally accumulated through trade. Nevertheless, from the perspective of a national economy and its internal trade and distribution network, it is useful to view distribution as largely secondary, with the volume of its business determined, within limits, by the nature and volume of productive activities generating tradeable, non-ephemeral commodities. Such a view does not imply that one sort of activity is superior to another, nor does it deny the possibility that improved trading arrangements can make a given level of production more effective in supplying use-values, or that it can stimulate productive activities more generally. It does mean that an increase in commodity production is necessary for a sustained increase in distribution activities, although at the same time it is true that tradeable commodities that are unable to reach their markets become useless junk.

The expansion of this sector is therefore limited by the expansion of the commodity producing sector. Within these limits, competition is of the nature of a zero-sum game, where a relatively fixed quantity is being divided between many participants. Therefore, although it is essential that this sector be flexible and responsive enough to deal with any increase in the volume of output, it cannot be seen as a major source of growth.

Nevertheless, this sector is capable of accumulating investible surplus: more than one third of shopkeepers indicated that they had earned more than Shs 1,000 in the previous month. This was true even though more than one half of all shopkeepers refused to disclose their incomes, and there is reason to believe that those refusing were often high income earners. ${ }^{4}$

4 The non-response of Asian shopkeepers was particularly high, and they were clearly the highest income earners in all sub-groups in which they were represented. 
For the 38 per cent (of those disclosing their incomes) who were earning between Shs 150 and Shs 999 per month, shopkeeping provided a reasonable income, comparable to that of wage earners, but not enough to be a source of capital accumulation or even a basis from which an expansion of inventories and hence of trade could be readily undertaken. Nevertheless, most of this group had been in the business for more than three years ( 71 per cent of all shopkeepers), and were apparently intending this to be a permanent source of income (only 9 per cent were looking for a job).

Among the shopkeepers there was also a fringe of more marginal operators, made up of some combination of: the 22 per cent who had arrived in town during the past three years; the 9 per cent who were looking for a job; the 13 per cent who had been shopkeepers for less than one year, and the 27 per cent (of those disclosing their incomes) who earned less than Shs 150 per month.

Street-traders made up another layer of retailers, existing in the nooks and crannies left by the shopkeepers. Virtually none of them earned incomes that might make accumulation of capital a real possibility, but about half of them (47 per cent) earned incomes over Shs 150 per month, i.e. incomes comparable to those of wage earners. This is especially remarkable in the light of two features of this group: its low educational level and its relative growth. Whereas 41 per cent of wage earners have no more than four years of schooling, 80 per cent of the street-traders fall in the same category. And whereas 17 per cent of all non-wage earners were under 25 years, 31 per cent of the street-traders were under 25 . On the other hand over half ( 53 per cent) of all street-traders earned less than Shs 150 per month; almost one in four ( 24 per cent) was looking for a job; 30 per cent had arrived in town within the last three years; and the 24 per cent who had been pursuing this activity for less than one year constituted a large proportion in comparison with other non-wage activities (average 15 per cent). Even so, it was also true that at least 30 per cent of the total number were persons who had been thus engaged for more than one year, even though they earned less than Shs 150 per month. 
Finally bar-keeping was rather similar to street-trading, though it provided incomes of at least Shs 150 per month for a somewhat larger proportion ( 60 per cent instead of 47 per cent) of its participants. Again there were none in the sample who appeared to be in a position to accumulate capital on a significant scale, though the high proportion earning reasonable incomes, combined with the fact that no less than 57 per cent of this group had been engaged in this particular activity for at least three years, suggested a stable and relatively attractive source of income.

In this activity there was also a marginal group made up of a combination of: the 40 per cent who earned less than Shs 150 per month; the 29 per cent who had been engaged in this activity for less than one year; the 26 per cent who had been in town less than four years; and the 17 per cent who were looking for a job.

It appears then, that the retailing sector was arranged in three tiers. At the top were primarily non-A frican shopkeepers who earned high incomes and many of whom were in a position to accumulate capital. Though the uses to which such resources were put could not be determined, it was suggested that many local manufacturing activities were probably originally financed from capital accumulated through trading activities.

The second layer of this sector afforded reasonable income to participants, but these were not of sufficient size to make accumulation and growth a likely possibility. Furthermore, given the limits imposed on the development potential of this sector by the scale of productive activities elsewhere in the economy, the net effect of any such potential growth would result primarily in a change in the ranking order of individual participants in the sector, and concentration at the higher levels would mean displacement or marginalization at the lower levels, though this might well entail a shift of resources from consumption to investment.

The implied competition between these two parts of the retailing sector accounts for the discrimination so generally practised against the more irregular traders. In Tanzania it appears reasonable to assume that the relative lack of harassment of such traders, which led in 1973 to the complete abolition of urban trading licences, has been related to the 
Asian domination of shopkeeping activities. ${ }^{5}$ By the same token, the increasing role played by government-controlled retail outlets augurs ill for the irregular traders in future. ${ }^{6}$ It should be noted that there seems to be no general justification for a policy restricting irregular traders. They provide a legitimate service by effectively decentralizing the retailing structure and only if competition led to substantial irregularity of supplies, or to problems with shady business practices employed by the more mobile and hence less accountable traders, would there be a case for restriction or control. Alternatively, to the extent that such competition cuts retailing margins it transfers income from those engaged in this sector to those purchasing the commodities so traded, and this results in lower wages and incomes in this sector, and a lowering of the cost of reproduction of all labour. This indicates why the more established traders are normally seeking protection from such competition, and why other groups apart from the irregular traders often encourage competition.

The competition between the lower two groups in the sector - namely the established and the marginal street traders - is similar. While the issuing of trading licences limits the competition which street-traders constitute for shopkeepers, it also protects the established street-traders from unlimited competition from below. In urban Tanzania this pressure has been less severe than elsewhere, partly because rates of net migration have been more moderate, partly because the growth in urban formal sector employment has kept pace over long periods with the growth in the urban labour force. ${ }^{7}$ It is a common observation that street-traders of all kinds have been noticeably less numerous in Dar es Salaam than elsewhere in larger African cities. On the other hand the survey did show that in the retailing sector a substantial number of

550 per cent of shopkeepers in the 1971 survey were Asian, and this included virtually all of those owning larger shops. NUMEIST, vol. IV.

6 There are recent reports of harassment of irregular traders in Dar es Salaam. See, for example, 'Tanzania bans maize selling in streets', East African Standard, 24 July 1974.

7 Dar es Salaam enumerated employment was 29,443 (African: regular and casual) in 1961 and 67,521 (citizens and casual) in 1969. This represents an increase of 129 per cent over eight years, or just under 11 per cent per annum. Source:

Employment and Earnings, 1962 and 1969. 
marginal (in terms of income) traders existed, and it is likely that they exerted a depressing influence on incomes in this sector. While this entailed a benefit to consumers at one level, if it undermines the core of permanent and established traders who make up the bulk of those involved in the trade, it may ultimately lead to a destabilization of retailing. It may also exacerbate the net migration problem by giving larger numbers of migrants a flimsy toe-hold in the urban economy, which is just enough to enable them to play the urban lottery and keep them from returning to the rural areas.

\section{Accommodation}

The third major group of self-employed are those who contribute towards the provision of accommodation. In general, the situation in this respect was relatively easy in Tanzania's urban areas. The reason for this lay primarily in the virtual absence of land-hoarding and land-speculation following the government's very strict regulations concerning land-ownership, under the terms of which a title to land consists merely of a right of occupancy, due to residing on, or actively working on, a piece of land. Although there has been some abuse of this system, it has on the whole created a situation in which access to land has been relatively easy and hence house-ownership relatively widespread, with 43 per cent of household heads paying no rent, and with rent payment amounting to no more than 12-14 per cent of the household head's income for virtually all other respondents, rising to 20 per cent only for the very lowest income earners.

Housing generally played a very important role in terms of social security. In our interviews both with residents of the poorest areas of the cities and with wage earners at their place of work, a constantly recurring theme was the idea that people saved in order to build a (concrete-block) house, from which they hoped to rent rooms so as to provide themselves with a steady basic income, especially once they were retired. That this dream was realistic, is indicated by the fact that almost 60 per cent of all household heads over 50 years of age owned a house in the city.

The role of housing income as secondary or retirement income, as well as the fact that access to such income was very broadly based, emerged clearly from the survey. Thus almost 60 per cent of reported incomes 
from house rental fell below Shs 150 per month; 85 per cent of those with such incomes had been in the city for more than ten years; almost half of those with rental incomes were over 50 years of age; and more than one-third currently received wage incomes in addition to their rental incomes.

\begin{abstract}
A further reason for this high degree of decentralization in the provision of housing accommodation was the fact that much of the housing so constructed was built by self-help, with the (possible) assistance of various sub-contractors usually employed on a jobbing basis.
\end{abstract}

The work of contractors tended to be irregular as a result, and 22 per cent of them had worked only three days or less during the previous week. On the other hand, the work required knowledge and resources which were not easily acquired, with the result that no less than 71 per cent of contractors had been in this business for more than three years, and only 14 per cent had arrived in the city within the past three years (compared to 42 per cent of wage earners).

Partly due to the irregularity of work, and partly due to the substitutability of self-help work for contract work, incomes were reasonable but not high, with virtually no-one earning more than Shs 1,000 per month, but with the majority receiving incomes comparable to those of wage earners. Nevertheless, this still left 36 per cent with incomes of less than Shs 150 in the previous month, a fact which partially explains the symbiotic relationship between wage-employment in larger scale contracting and this small-scale self-employing contracting activity. Thus only 27 per cent of contractors had never held wage employment (this was by far the lowest proportion for any of the self-employed categories - average 54 per cent), and 33 per cent were looking for a job at the time of the interview (average 16 per cent).

On balance there was little evidence that accumulation, on any large scale was taking place in this sector. In general, incomes were not large enough to allow this, although it should be said that relatively small amounts of capital would be required to enter the construction industry on a larger scale. But here again the fact that the 'modern' 
sector of this industry was dominated by the Asian community was of some importance. In a separate study of that industry the author found that because of the close ties between material suppliers, builders and architects, an African contractor had little chance of establishing himself in this sector. The 'modern' sector of the industry was dominated by non-Africans and the market for large buildings was controlled by a group of about fifteen firms who operated in a very 'soft' market where competition was more apparent than real, where tender prices were very volatile and where profit margins were large. That study further suggested that this problem became worse as demand for 'modern' buildings grew. But even then there was little evidence of small local contractors being drawn up by the suction thus created. Indeed it appeared that unless standards of building were adjusted and credit facilities and material supplies made available to smaller contractors, their chances of expanding beyond the boundaries of the small residential housing market were extremely limited. On the other hand if a substantial part of the 'modern' sector's demand could be met by local builders, dealing with much simplified designs and structures, the effects in terms of saving foreign exchange, the creation of employment and the encouragement of linkages of various kinds could be significant.

\section{Conclusions}

This paper set out to attempt to come to terms with the concept of the 'informal sector' as a classification of a syndrome of urban poverty. The tentative conclusion is that the urban poor are crowded into a series of activities which are highly differentiated in nature but which have in common one major and dominant at tribute: their ability to accumulate capital to raise the forces of production is both limited by and dependent upon the activities of the 'modern' sector, as an extension of the international capitalist system. This is because this sector is able to take over any sphere of production or any market which may be developed through non-capital intensive activities. In the course of such an extension of international capital, the growing 'informal' activities will be destroyed. Though at times others may be generated which feed in to these newly created 'modern' enterprises, a net loss will normally be incurred in the shift.

It follows that the economic areas in which such 'informal' activities are located, are those which capital intensive mass production has not yet 
penetrated. This is sometimes due to the nature of the demand being met - personal services, retail trading, sub-contracting in housing, in which areas extensive capital intensive production is for the moment unlikely, and therefore a great deal of (living) labour time is expended in these activities. But this labour time does not exchange 'equally' in the market. Rather it exchanges for goods embodying less labour time (i.e. goods whose prices do not fully reflect the greater efficiency of their production). This process involves a transfer of surplus to the 'modern' sector, within which this surplus may be shared by the wage earners involved in the production of such commodities, although this would apply primarily to industries producing for 'soft' (domestic or international) markets.

In some other cases such small-scale producers are simply exploiting particular niches in the market, and in this way have the opportunity to grow independently, but always subject to the constraint that international capital and/or technology is capable of intervening to take over. It may be noted that this possibility is, of course, crucially dependent on the state of international capital markets, with the well-known Latin American result, that the cumulative growth of local accumulation is likely to be more sustained during periods of international crisis, when international capital is less readily available. However the Latin American experience also suggests that a change in this international climate will return one to the status quo ante, almost irrespective of how far local development has progressed.

At this stage of the work, firm conclusions as to the long-run implications of the processes identified cannot be drawn, but it would appear that it is this process and its attendant frequent disruptions of patterns of accumulation which lie at the heart of the debate concerning the limits or the 'special' difficulties of peripheral capitalism. It is this process which stunts the growth of the small-scale productive sectors: either completely containing it by decapitating any foray into mass production by parts of this sector through the direct introduction of foreign, or foreign government (cum foreign technology) enterprises; or by vastly accelerating the broadly based, widely linked development of a particular productive activity so that a very few producers with relatively few employees and few linkages come to dominate these new activities in a short space of time. In either 
case the small-scale sector remains behind, further weakened. In the first case some of the most promising enterprises of that sector go to the wall and the capital invested in them is usually destroyed; in the second case a few former 'informal sector' entrepreneurs make it, but the effect is much the same, since-their adoption of the latest technology also means a discontinuous leap from their previous technology, and this technology is generally not acquired through surplus generated in the 'informal sector' but through credit in the formal sector. It hence represents simply an expansion of the 'formal' sector within the limits of the resources available from that sector, rather than additional accumulation generated outside of its confines.

It is for these reasons that detailed observations of 'informal sector' activities always reveal great vitality, considerable technological developments and every sign of responsive and adaptable growth, while the larger picture remains one of a seemingly endless perpetuation of the sector and its problems of poverty and low productivity. It is also for the reasons given, that these two sets of observations are seen to be compatible. Indeed we should expect to find them wherever an economy is exposed to open competition from a far more advanced technology and an expansive international capital market. 